\title{
Use of TBzTD as Noncarcinogenic Accelerator for ENR/SiO 2 Nanocomposites: Cured Characteristics, Mechanical Properties, Thermal Behaviors, and Oil Resistance
}

\author{
Laksamon Raksaksri, ${ }^{1}$ Saowaroj Chuayjuljit, ${ }^{1}$ \\ Phasawat Chaiwutthinan, ${ }^{2}$ and Anyaporn Boonmahitthisud ${ }^{1}$ \\ ${ }^{1}$ Department of Materials Science, Faculty of Science, Chulalongkorn University, Bangkok 10330, Thailand \\ ${ }^{2}$ MTEC, National Science and Technology Development Agency (NSTDA), Thailand Science Park, Khlong Luang, \\ Pathum Thani 12120, Thailand \\ Correspondence should be addressed to Anyaporn Boonmahitthisud; anyaporn.b@chula.ac.th
}

Received 6 April 2017; Accepted 7 June 2017; Published 31 July 2017

Academic Editor: Domenico Acierno

Copyright ( 2017 Laksamon Raksaksri et al. This is an open access article distributed under the Creative Commons Attribution License, which permits unrestricted use, distribution, and reproduction in any medium, provided the original work is properly cited.

\begin{abstract}
This study reported the use of tetrabenzylthiuram disulphide (TBzTD) as a noncarcinogenic accelerator in a traditional sulfur curing system of epoxidized natural rubber $(\mathrm{ENR}) /$ nanosilica $\left(\mathrm{nSiO}_{2}\right)$ composites. ENR used in this work was synthesized via in situ epoxidation of natural rubber (NR) in the presence of performic acid generated from the reaction of formic acid and hydrogen peroxide at $50^{\circ} \mathrm{C}$ for $8 \mathrm{~h}$ to acquire the epoxide content of about $40 \mathrm{~mol} \%$. Accordingly, the resulting ENR was referred to as ENR 40. The curing characteristics, mechanical properties, thermal behaviors, dynamic mechanical properties, and oil resistance of ENR $40 / \mathrm{nSiO}_{2}$ nanocomposites filled with three loadings of $\mathrm{nSiO}_{2}(1,2$, and 3 parts per hundred parts of rubber) were investigated and compared with NR and neat ENR 40. The results revealed that the scorch and cure times of ENR $40 / \mathrm{nSiO}_{2}$ nanocomposites were slightly longer than those of NR but slightly shorter than those of ENR 40. The tensile properties and tear strength for both before and after aging of all ENR $40 / \mathrm{nSiO}_{2}$ nanocomposites were higher than those of ENR 40, while the glass transition temperature, storage modulus at $-65^{\circ} \mathrm{C}$, thermal stability, and oil resistance of $\mathrm{ENR} 40 / \mathrm{nSiO}_{2}$ nanocomposites were higher than those of $\mathrm{NR}$ and ENR 40.
\end{abstract}

\section{Introduction}

Natural rubber (NR) is one of the most important natural biosynthesis polymers and renewable resources that possesses excellent mechanical properties owing to its ability to crystallize upon stretching (strain-induced crystallization), but its thermal, oxidation, and oil resistance cannot compete with some special purpose synthetic rubbers [1-12]. This is a normal consequence of its highly unsaturated hydrocarbon chain structure and nonpolar nature [2-4]. However, the certain properties of NR can be improved via chemical modifications at the carbon-carbon double bonds $(\mathrm{C}=\mathrm{C})$ in its isoprene unit to produce functionalized specialty rubbers with an expanded range of physical and chemical properties. The controlled partial epoxidation of NR to form epoxidized
NR (ENR) is one of the important methods that introduce a new reactive group into the NR backbone, leading to the new and useful properties. This involves the random introduction of polar epoxide (oxirane) groups onto the $\mathrm{C}=\mathrm{C}$ in the repeat unit of NR by the two consecutive reactions. The first one included the "in situ" formed peracid generated from the endothermic reaction of hydrogen peroxide $\left(\mathrm{H}_{2} \mathrm{O}_{2}\right)$ and the acid, followed by the exothermic epoxidation reaction, leading to an increased polarity and a reduction in the $\mathrm{C}=\mathrm{C}$ in the rubber chains $[5,8,9,12-18]$. As a consequence, ENR would have oil and oxidation resistance comparable to some of the synthetic rubbers, depending on the extent of epoxidation (mol\% epoxidation) $[5,9,10,12]$. It has been reported that ENR with $50 \mathrm{~mol} \%$ epoxidation exhibits oil resistance similar to that of medium-acrylonitrile-content nitrile rubber and 


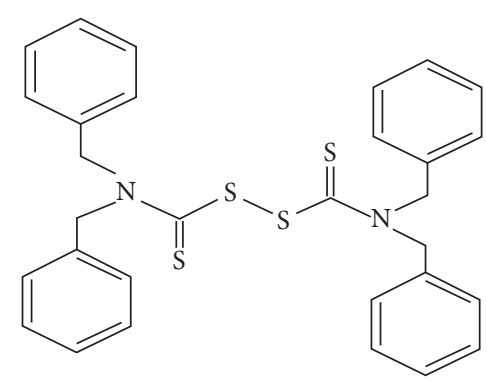

Scheme 1: Molecular structure of tetrabenzylthiuram disulphide (TBzTD).

superior to that of chloroprene rubber $[9,12,19]$. As the level of epoxidation increases more than $50 \mathrm{~mol} \%$, the ENR products become harder and of less resilience and elasticity at room temperature (RT), whereas the products of lower epoxide content are typical elastomers with less oil resistance $[8,10,17]$. In this study, ENR with medium epoxide content (approximately $40 \mathrm{~mol} \%$ ) was synthesized from concentrated NR latex to impart higher oil resistance compared to the NR while maintaining both elasticity and strain crystallization of the products. The resulting ENR was then vulcanized by a traditional sulfur curing system using an organic accelerator in a usual manner applicable for NR. Tetrabenzylthiuram disulphide (TBzTD, $\mathrm{C}_{30} \mathrm{H}_{28} \mathrm{~N}_{2} \mathrm{~S}_{4}$, Scheme 1) was selected for using as a safe (noncarcinogenic) accelerator to reduce the generation of hazardous nitrosamines in rubber compounds. Nitrosamines are generally generated from the rubber products during mixing, curing, and storage when using amine containing accelerators such as tetramethylthiuram disulfide (TMTD) [7, 20]. With this respect, the TBzTD, a fast curing accelerator with no secondary amine, has been developed to replace the TMTD, resulting in the nitrosamine free cure.

Recently, reinforcement of rubbers with inorganic nanoparticles, even at a very low loading, can significantly improve their mechanical and thermal properties $[9,10,19$, 21-25]. To achieve the desired properties, the nanofillers must sufficiently disperse in the rubber matrix, as poor dispersion leads to the obvious decrease in the performance properties of the nanocomposites. Nanosilica $\left(\mathrm{nSiO}_{2}\right)$ is an inorganic filler with a large number of hydroxyl $(-\mathrm{OH})$ groups on its surface and thus provides strong filler-filler interactions to generate $\mathrm{nSiO}_{2}$ aggregates and agglomerates. However, the epoxide groups of ENR can effectively cause a specific interaction between $\mathrm{nSiO}_{2}$ and ENR via hydrogen bonding, leading to a decrease in filler-filler interaction and an increase in compatibilization [9, 22-24]. With this respect, ENR nanocomposites can be directly prepared using $\mathrm{nSiO}_{2}$ as a nonblack reinforcement without the aid of any coupling agents or pretreatments $[9,12]$. Therefore, their unique properties can be combined in order to improve the application properties of the resulting nanocomposites. To the best of our knowledge, use of the TBzTD as the nitrosamine free accelerator in the sulfur curing of the $\mathrm{ENR} / \mathrm{nSiO}_{2}$ nanocomposites has never been reported. Therefore, the mechanical properties and thermal and dynamic mechanical properties, as well as oil resistance of the prepared $\mathrm{ENR} / \mathrm{nSiO}_{2}$ nanocomposites, were investigated and compared with those of the neat NR and ENR.

\section{Experimental Section}

2.1. Materials. High ammonia concentrated NR latex with a $60 \%$ dry rubber content (DRC), polyalcohol ethylene oxide condensate (Terric 16A-16), sulfur, zinc oxide ( $\mathrm{ZnO}$ ), stearic acid, Voltamol, and bentonite were supplied from the Rubber Research Institute of Thailand (Thailand). TBzTD manufactured by Performance Additive Co. (Italy) was purchased from Behn Meyer Chemicals Co. (Thailand). Formic acid and $\mathrm{HCOOH}(98 \%)$ manufactured by Fisher Chemical Co. (UK) and $\mathrm{H}_{2} \mathrm{O}_{2}$ (35\%) manufactured by Chem-Supply Pty Co. (Australia) were purchased from Myscience Co. (Thailand) and RCI Lab Scan Co. (Thailand), respectively. Nano-SiO $\mathrm{S}_{2}$ having particle size of about $12 \mathrm{~nm}$ and specific surface area of $175-225 \mathrm{~m}^{2} \mathrm{~g}^{-1}$ manufactured by Sigma Aldrich (Singapore) was purchased from A.C.S. Xenon Co. (Thailand). Sodium carbonate and methanol were purchased from Merck Thailand Co. (Thailand) and RCI Lab Scan Co. (Thailand), respectively. ASTM oil number 1 (IRM 901) and ASTM oil number 3 (IRM 903) were purchased from Chemical Innovation Co. (Thailand). All materials were used as received without further purification.

2.2. Preparation and Characterization of ENR. The ENR was synthesized via in situ latex epoxidation of NR by performic acid generated from the reaction between $\mathrm{HCOOH}$ and $\mathrm{H}_{2} \mathrm{O}_{2}$. Prior to epoxidation, NR latex was diluted with distilled water to reduce the DRC from $60 \%$ to $20 \%$ and then stabilized with the nonionic surfactant Terric 16A-16 (3 parts by weight per hundred of rubber, phr) at RT under stirring for $1 \mathrm{~h}$. The assigned amounts of $\mathrm{HCOOH}$ ( $1 \mathrm{M}$ of isoprene unit) and $\mathrm{H}_{2} \mathrm{O}_{2}(0.75 \mathrm{M}$ of isoprene unit) were then added to the stabilized NR latex. The $\mathrm{HCOOH}$ was fed dropwise over $10-15 \mathrm{~min}$ at $40^{\circ} \mathrm{C}$, followed by raising the temperature to $50^{\circ} \mathrm{C}$ within $10 \mathrm{~min}$ prior to adding the $\mathrm{H}_{2} \mathrm{O}_{2}$ over $5-10 \mathrm{~min}$ with continuous stirring. The reaction was allowed to proceed at $50^{\circ} \mathrm{C}$ for $8 \mathrm{~h}$. The obtained products were sampled and coagulated by an excess $95 \%$ (v/v) methanol, filtered, washed well with distilled water, soaked in $10 \%(\mathrm{w} / \mathrm{w})$ sodium carbonate solution for $30 \mathrm{~min}$, washed again until being neutral, pressed into a thin sheet, and dried at $60^{\circ} \mathrm{C}$ for $48 \mathrm{~h}$ until at a constant weight before analysis.

The mol\% epoxidation of the resulting ENR was examined by Fourier transform infrared (FT-IR) spectroscopy on a Nicolet 6700-FT-IR (USA) over a frequency range of $400-4000 \mathrm{~cm}^{-1}$ and by proton nuclear magnetic resonance spectroscopy $\left({ }^{1} \mathrm{H}-\mathrm{NMR}\right)$ on an Avance III HD $500 \mathrm{MHz}$ NMR spectrometer (Bruker, Germany). The mol\% epoxidation was calculated from (1) using data from the FT-IR peaks at 870 and $835 \mathrm{~cm}^{-1}[14,26]$.

$$
\text { Mol\% epoxidation }=\left[\frac{A_{870}}{\left(A_{870}+A_{835}\right)}\right] \times 100,
$$

where $A_{870}$ and $A_{835}$ are the absorbance at wavenumbers 870 and $835 \mathrm{~cm}^{-1}$, respectively. 
To estimate the mol\% epoxidation from the ${ }^{1} \mathrm{H}-\mathrm{NMR}$ analysis, two characteristic peaks were considered in relation with $(2)[8,9,13,24]$ :

$$
\text { Mol\% epoxidation }=\left[\frac{A_{2.7}}{\left(A_{2.7}+A_{5.14}\right)}\right] \times 100,
$$

where $A_{2.7}$ and $A_{5.14}$ are the integrate areas under the ${ }^{1} \mathrm{H}-\mathrm{NMR}$ peaks at about $2.7 \mathrm{ppm}$, representing the epoxide proton, and at about $5.14 \mathrm{ppm}$, representing an olefinic proton, respectively.

The glass transition temperature $\left(T_{\mathrm{g}}\right)$ of the sample was evaluated by differential scanning calorimetry (DSC) on a Mettler Toledo DSC 1 STARe System (Switzerland) at a heating/cooling rate of $5^{\circ} \mathrm{C} \mathrm{min}^{-1}$ under a $\mathrm{N}_{2}$ flow of $20 \mathrm{~mL} \mathrm{~min}^{-1}$ from -80 to $20^{\circ} \mathrm{C}$.

2.3. Preparation and Characterization of $\mathrm{ENR} / n \mathrm{niO} \mathrm{Nano}_{2} \mathrm{Na}$ composites. The as-synthesized ENR was compounded with $\mathrm{nSiO}_{2}(0,1,2$, and $3 \mathrm{phr})$ by latex compounding. The obtained nanocomposites were sampled and coagulated by an excess 95\% (v/v) methanol, filtered, washed well with distilled water, soaked in $10 \%(\mathrm{w} / \mathrm{w})$ sodium carbonate solution for $30 \mathrm{~min}$, and washed again until being neutral. The $\mathrm{ENR} / \mathrm{nSiO}_{2}$ nanocomposites were mixed with $\mathrm{ZnO}$ (5 phr), stearic acid ( 2 phr), TBzTD (6 phr), and sulfur ( $0.5 \mathrm{phr})$ in an internal mixer (MX500-D75L90, Thailand) at $70^{\circ} \mathrm{C}$ for $9 \mathrm{~min}$ and then sheeted on an open two-roll mill at RT for $1 \mathrm{~min}$. The cure characteristics of the different stocks were determined using a moving die rheometer (MDR, A0225-rheo Tech Techpro, USA) at $150^{\circ} \mathrm{C}$ according to ASTM D5289. The respective scorch time $\left(t_{\mathrm{s} 2}\right)$, cure time $\left(t_{90}\right)$, minimum torque $\left(M_{\mathrm{L}}\right)$, maximum torque $\left(M_{\mathrm{H}}\right)$, and torque difference $\left(M_{\mathrm{H}}-M_{\mathrm{L}}\right)$ were obtained from the rheograph. The cure rate index (CRI) was then calculated from $(3)[1,7,18]$ :

$$
\mathrm{CRI}=\frac{100}{\left(t_{90}-t_{\mathrm{s} 2}\right)}
$$

The ENR well-mixed compound was then press-cured into $3 \mathrm{~mm}$ thick sheet using a compression molding machine (LP-S-20, LabTech Engineering, Thailand) at $150^{\circ} \mathrm{C}$ according to the $t_{90}$ obtained from the MDR. For comparison, NR vulcanizate was also prepared using the same sulfur curing process as above.

2.4. Testing and Characterization of the Vulcanizates. The tensile properties (tensile strength, modulus at 300\% strain (M300), and elongation at break) of the vulcanizates were measured on the standard dumbbell-shape specimen according to ISO 37 Type II using an Instron universal testing machine (5840 series single column systems, USA) with a $1 \mathrm{kN}$ load cell and at a crosshead speed of $500 \mathrm{~mm} \mathrm{~min}^{-1}$. The tear strength was measured according to ASTM D624 on an angle-shaped sample with the same universal testing machine at a strain rate of $500 \mathrm{~mm} \mathrm{~min}^{-1}$. At least five specimens were examined for each test.

The thermal aging of the sample was performed in a universal oven (Model UF55, Germany) with air circulating system at $70^{\circ} \mathrm{C}$ for $72 \mathrm{~h}$ according to ASTM D573. After aging, the specimen was conditioned at RT for at least $16 \mathrm{~h}$ prior to determining the tensile properties and tear strength in the same manner as the unaged specimen. The percentage retention in properties was calculated from the following equation [4]:

$$
\text { Retention }(\%)=\left(\frac{\text { Value after aging }}{\text { Value before aging }}\right) \times 100 \text {. }
$$

The thermal stability of the sample was measured by means of thermogravimetric analysis (TGA) on a Mettler Toledo, TGA/SDTA $851^{\mathrm{e}}$ instrument (Switzerland), operating under a $\mathrm{N}_{2}$ atmosphere at a heating rate of $20^{\circ} \mathrm{C} \mathrm{min}-1$ within the temperature range of $50-1,000^{\circ} \mathrm{C}$. The dynamic mechanical analysis (DMA) of the sample was performed on a Mettler Toledo DMA/SDTA $861^{\mathrm{e}}$ instrument (Switzerland) under a shear mode at a constant frequency of $1 \mathrm{~Hz}$ and a heating rate of $3^{\circ} \mathrm{C} \mathrm{min}^{-1}$ over a temperature range of -50 to $50^{\circ} \mathrm{C}$ and under a $\mathrm{N}_{2}$ flow.

The oil resistance was determined by measuring the percentage volume change of the sample after a $72 \mathrm{~h}$ immersion period in two types of oil, ASTM oil number 1 and number 3, at $100^{\circ} \mathrm{C}$. Prior to immersion, the test specimen was weighted in both air and distilled water at RT. After immersion, the test specimen was removed from the respective oils, cooled to RT by transferring to a cool and clean test oil for about $30 \mathrm{~min}$, and then dipped quickly in acetone at RT and wiped lightly with filter paper to remove the excess oil from the surface prior to weighing again in both air and distilled water. The percent change in volume was then evaluated using (5) according to ASTM D471-79:

$$
\% \Delta V=\frac{\left[\left(M_{3}-M_{4}\right)-\left(M_{1}-M_{2}\right)\right]}{\left(M_{1}-M_{2}\right)} \times 100,
$$

where $M_{1}$ and $M_{2}$ are the initial mass ( $\mathrm{g}$ ) of the specimen in air and distilled water, respectively, and $M_{3}$ and $M_{4}$ are the mass ( $\mathrm{g}$ ) of the specimen in air and distilled water after immersion, respectively.

\section{Results and Discussion}

3.1. Characterization of Unvulcanized Samples. Figure 1 shows the representative FT-IR spectra of the samples over a frequency range of $4000-400 \mathrm{~cm}^{-1}$. The characteristic peaks of NR (Figure 1(a)) that appeared at 3037, 2850, 1660, 1450, 1375 , and $835 \mathrm{~cm}^{-1}$ are assigned to the $=\mathrm{C}-\mathrm{H}$ stretching, $\mathrm{C}-\mathrm{H}$ stretching, $\mathrm{C}=\mathrm{C}$ stretching, $\mathrm{C}-\mathrm{H}$ bending of $\mathrm{CH}_{2}, \mathrm{C}-\mathrm{H}$ bending of $\mathrm{CH}_{3}$, and $=\mathrm{C}-\mathrm{H}$ bending, respectively $[3,8,15$, 24]. The new characteristic peaks that appeared at 1240 and $870 \mathrm{~cm}^{-1}$ (Figure 1(b)) are assigned to the symmetric stretching and asymmetric stretching of epoxide ring, respectively $[5,8,15,16,18,24-27]$. This confirmed the formation of epoxide or oxirane rings from the reaction of performic (generated in situ by the reaction of $\mathrm{HCOOH}$ and $\mathrm{H}_{2} \mathrm{O}_{2}$ ) with the $\mathrm{C}=\mathrm{C}$ on the NR molecules. The absorbance at $870 \mathrm{~cm}^{-1}$ was then compared with that of the residue olefinic peak $(\mathrm{C}=\mathrm{C}$ cis $)$ at $835 \mathrm{~cm}^{-1}$ to evaluate the mol\% epoxidation. In 


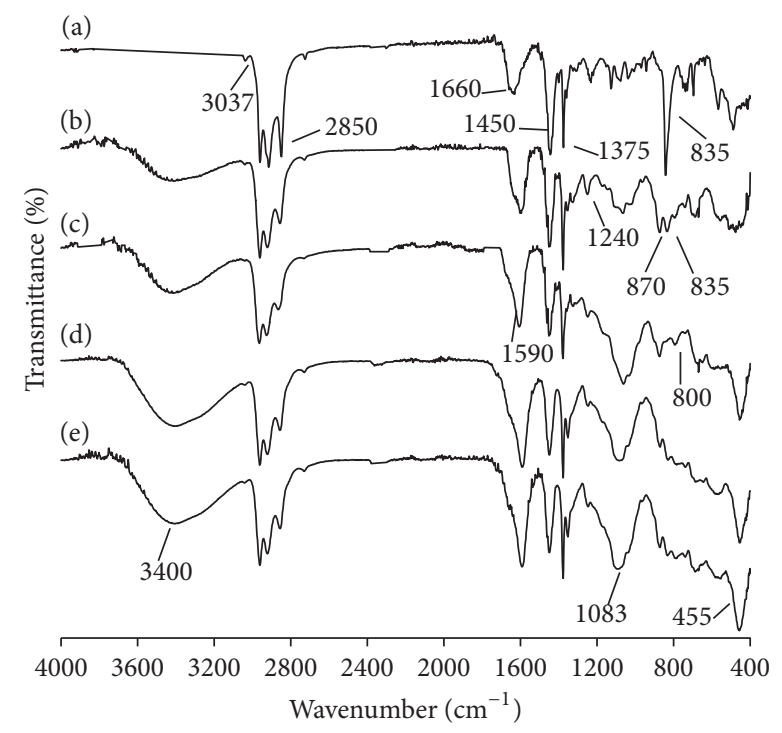

FIGURE 1: FTTR spectra of (a) NR, (b) ENR 40, and nanocomposites

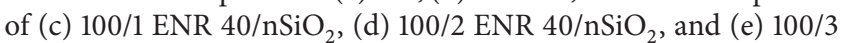
ENR $40 / \mathrm{nSiO}_{2}$.

addition, the broad peak at about $3400 \mathrm{~cm}^{-1}$ (Figure 1(b)) indicates the presence of -OH groups in the ENR molecules, resulting from a partial opening of epoxide ring during ENR preparation $[5,15,16,24]$. Figures $1(\mathrm{c})$ and $1(\mathrm{~d})$ also show broad peaks at about $3400 \mathrm{~cm}^{-1}$, which are mainly owing to the $\mathrm{O}-\mathrm{H}$ stretching vibration of $-\mathrm{OH}$ groups on $\mathrm{nSiO}_{2}$ surfaces and from the opening of epoxide ring, and so the peak size increased with increasing $\mathrm{nSiO}_{2}$ loading. The peak at $1590 \mathrm{~cm}^{-1}$ is attributed to the bending vibration of the $\mathrm{O}-\mathrm{H}$ bond in the adsorbed water molecules on $\mathrm{nSiO}_{2}$ surfaces. The intensive peaks at about $1083 \mathrm{~cm}^{-1}$, together with the less intensive peaks at 800 and $455 \mathrm{~cm}^{-1}$, are attributed to the asymmetric stretching vibration, symmetric stretching vibration, and asymmetric bending vibration of $\mathrm{Si}-\mathrm{O}-\mathrm{Si}$, respectively [24-26].

The presence of epoxide rings in ENR molecules was also confirmed by the ${ }^{1} \mathrm{H}$-NMR analysis. The ${ }^{1} \mathrm{H}$-NMR spectrum of the synthesized ENR sample revealed two peaks at 2.7 and $1.3 \mathrm{ppm}$ (Figure 2), which represented the proton attached to the epoxide ring and the proton from a methyl group attached to the epoxide ring, respectively, while the peak at $5.14 \mathrm{ppm}$ represented the olefinic proton of the unreacted NR. In addition, the peak at $3.7 \mathrm{ppm}$ was attributed to some functional groups such as $-\mathrm{OH}$ and hydrofuran obtained from the opening of epoxide rings $[8,9,14,24]$. This is in agreement with the result of the FT-IR analysis that was previously mentioned.

DSC analysis was also used as a quantitative measurement for the mol\% epoxidation from the increased $T_{\mathrm{g}}$ of the synthesized ENR compared with that of the pure NR [5, 12-14]. It has been reported that, for the ENR with side ring-opening reaction, each mol\% epoxidation gives a $1.15^{\circ} \mathrm{C}$ increase in $T_{\mathrm{g}}$ [12]. The increased $T_{\mathrm{g}}$ of ENR was owing to the polar epoxide group that provided strong intermolecular interaction and

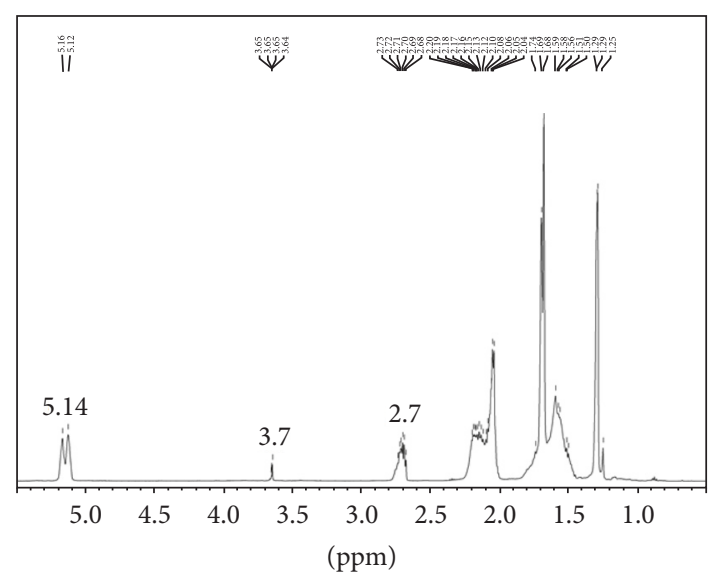

Figure 2: ${ }^{1} \mathrm{H}-\mathrm{NMR}$ spectrum of ENR 40.

so restricted the mobility of the ENR chains $[5,16,24]$. The DSC thermograms of the unvulcanized samples based on the second heating scan performed between -80 and $20^{\circ} \mathrm{C}$ are shown on the left side of Figure 3 and the obtained $T_{\mathrm{g}}$ values are summarized in Table 1 . As can be seen, $T_{\mathrm{g}}$ of the synthesized ENR $\left(-26.2^{\circ} \mathrm{C}\right)$ was higher than that of the NR $\left(-70^{\circ} \mathrm{C}\right)$ about $43.8^{\circ} \mathrm{C}$. Although $T_{\mathrm{g}}$ of ENR was much higher than that of NR, it was not significantly changed after adding different $\mathrm{nSiO}_{2}$ loadings, suggesting that the presence of $\mathrm{nSiO}_{2}$ had a small influence on $T_{\mathrm{g}}$ of the nanocomposites.

The calculated mol\% epoxidation of the synthesized ENR from the FT-IR (using (1)), ${ }^{1} \mathrm{H}-\mathrm{NMR}$ (using (2)), and DSC analyses was about 43,39 , and $38 \%$, respectively. Based on the mol\% epoxidation, the as-synthesized ENR was then denoted as ENR 40.

The MDR rheographs of the samples conducted at $150^{\circ} \mathrm{C}$ are shown in Figure 4, and the main cure characteristics $\left(t_{\mathrm{s} 2}, t_{90}, \mathrm{CRI}, M_{\mathrm{L}}, M_{\mathrm{H}}\right.$, and $\left.M_{\mathrm{H}}-M_{\mathrm{L}}\right)$ are all summarized in Table 2 . The sulfur vulcanization with unsaturated rubbers generally occurred through a free radical reaction initiated by accelerator. The resulting sulfur radicals further attack reactive allylic hydrogens in rubber chains to form sulfur crosslinks, and so the vulcanization depends upon the number of the allylic hydrogens [28]. $t_{\mathrm{s} 2}$ is the time required for the torque value to increase two units from $M_{\mathrm{L}}$, which corresponds to the premature vulcanization of rubber compound, while $t_{90}$ is the vulcanization time for optimum cure torque $[1,3]$. As can be seen, NR exhibited shorter $t_{\mathrm{s} 2}$ and $t_{90}$ than ENR 40 after being cured under the same condition. This is because NR possessed a higher level of unsaturation and reactive sites than ENR 40, and so the crosslinks started and reached the optimum cure torque in a shorter time $[1,18,28]$. Moreover, the high content of benzylthiuram substituents in the TBzTD accelerator may provide a steric hindrance to the limited crosslink sites of the ENR 40. However, the ENR 40 had higher CRI than the NR because the isolated $\mathrm{C}=\mathrm{C}$ in ENR reacted more rapidly than the contiguous $\mathrm{C}=\mathrm{C}$ in $\mathrm{NR}$, and also owing to the activation of the adjacent $\mathrm{C}=\mathrm{C}$ by the epoxide group in the $\operatorname{ENR}[9,10,13]$. 

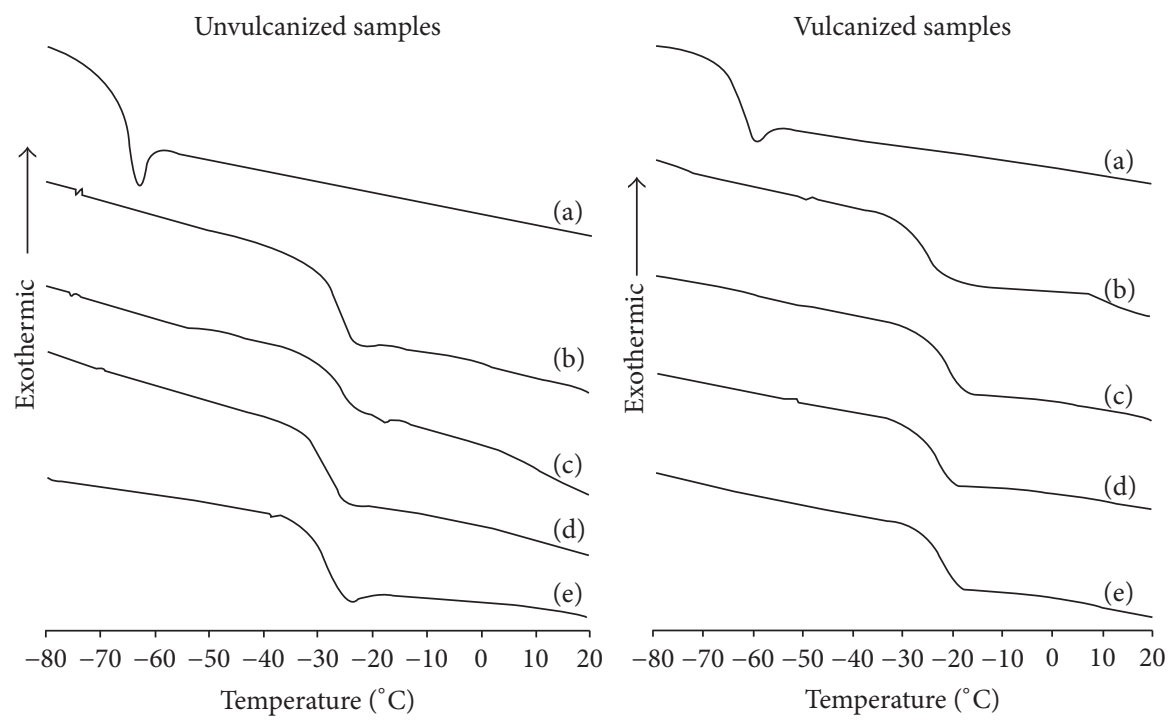

FIGURE 3: DSC thermograms derived from the second heating scan of (a) NR, (b) ENR 40, and nanocomposites of (c) 100/1 ENR 40/nSiO ,

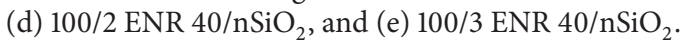

TABLE 1: Thermal properties of NR, ENR 40, and ENR 40/nSiO 2 nanocomposites obtained from DSC, DMA, and TGA analyses.

\begin{tabular}{|c|c|c|c|c|c|}
\hline \multirow{2}{*}{ Thermal properties } & \multirow{2}{*}{ NR } & \multirow{2}{*}{ ENR 40} & \multicolumn{3}{|c|}{ ENR $40 / \mathrm{nSiO}_{2}$} \\
\hline & & & $100 / 1$ & $100 / 2$ & $100 / 3$ \\
\hline \multicolumn{6}{|l|}{ DSC } \\
\hline$T_{\mathrm{g}}\left({ }^{\circ} \mathrm{C}\right)$ : unvulcanized & -68.2 & -26.2 & -24.3 & -27.2 & -25.7 \\
\hline$T_{\mathrm{g}}\left({ }^{\circ} \mathrm{C}\right)$ : vulcanized & -64.2 & -25.0 & -21.6 & -23.5 & -22.5 \\
\hline \multicolumn{6}{|l|}{ DMA } \\
\hline$E^{\prime}$ at $-65^{\circ} \mathrm{C}(\mathrm{MPa})$ & 404.2 & 670.1 & 905.5 & 1408.8 & 808.7 \\
\hline$T_{\mathrm{g}}\left({ }^{\circ} \mathrm{C}\right)$ at $E^{\prime \prime}$ peak & -53.8 & -15.9 & -14.8 & -19.3 & -15.5 \\
\hline$T_{\mathrm{g}}\left({ }^{\circ} \mathrm{C}\right)$ at $\tan \delta$ peak & -48.0 & -7.6 & -7.0 & -8.3 & -7.5 \\
\hline $\tan \delta_{\max }$ & 2.5 & 2.2 & 2.1 & 2.4 & 2.0 \\
\hline \multicolumn{6}{|l|}{ TGA and DTG } \\
\hline$T_{\text {onset } 1}\left({ }^{\circ} \mathrm{C}\right)$ & 226 & 251 & 252 & 252 & 248.7 \\
\hline$T_{\text {end set } 1}\left({ }^{\circ} \mathrm{C}\right)$ & 287 & 290 & 291.5 & 296 & 279.3 \\
\hline$T_{\max 1}\left({ }^{\circ} \mathrm{C}\right)$ & 268.7 & 281.7 & 275 & 284.8 & 268.5 \\
\hline$T_{\text {onset } 2}\left({ }^{\circ} \mathrm{C}\right)$ & 362.7 & 369.8 & 378.4 & 379.7 & 377 \\
\hline$T_{\text {end set 2 }}\left({ }^{\circ} \mathrm{C}\right)$ & 419.4 & 434 & 434.9 & 435 & 434.6 \\
\hline$T_{\max 2}\left({ }^{\circ} \mathrm{C}\right)$ & 384.7 & 391.7 & 402.7 & 399.2 & 401.3 \\
\hline$T_{50 \%}\left({ }^{\circ} \mathrm{C}\right)$ & 388.4 & 403 & 407 & 408 & 410.6 \\
\hline char (\%) & 6 & 6 & 13.4 & 15.9 & 16.6 \\
\hline
\end{tabular}

$t_{\mathrm{s} 2}$ and $t_{90}$ of the NR were also shorter than those of the ENR $40 / \mathrm{nSiO}_{2}$ nanocomposites. This again attributed to the higher level of the reactive sites in the NR molecules. Compared with the neat ENR 40, the nanocomposite containing 1 phr nSiO ${ }_{2}$ had lower $t_{\mathrm{s} 2}$ and $t_{90}$ because of the self-crosslinks or additional crosslinks from the specific interaction between the epoxide groups in the ENR 40 and -OH groups on the $\mathrm{nSiO}_{2}$ surface through hydrogen bonding [9, 22-24, 29]. However, the CRI of the ENR 40 nanocomposite with $1 \mathrm{phr}$ $\mathrm{nSiO}_{2}$ was lower than that of the neat ENR 40, indicating a slower rate of vulcanization. This is attributed to the adsorption of the basic accelerator on the $-\mathrm{OH}$ groups of the $\mathrm{nSiO}_{2}$ surface and so lowered the vulcanization rate of the nanocomposites $[9,25]$. Further increase in the $\mathrm{nSiO}_{2}$ loading to $2 \mathrm{phr}$ resulted in longer $t_{\mathrm{s} 2}$ and $t_{90}$, and a lower CRI because of the higher level of the adsorbed accelerator on the $\mathrm{nSiO}_{2}$ surface, which subsequently reduced the accelerator efficiency. However, at $3 \mathrm{phr} \mathrm{nSiO}_{2}, t_{\mathrm{s} 2}$ and $t_{90}$ were again shorter and the CRI was again increased owing to the agglomeration of $\mathrm{nSiO}_{2}$ particles in the nanocomposite that decreased the free $\mathrm{Si}-\mathrm{OH}$ groups and so reduced the accelerator being adsorbed on the $\mathrm{nSiO}_{2}$ surface.

$M_{\mathrm{L}}$ is commonly related to the viscosity of the uncured compound, while $M_{\mathrm{H}}$ is regarded to the elastic modulus 


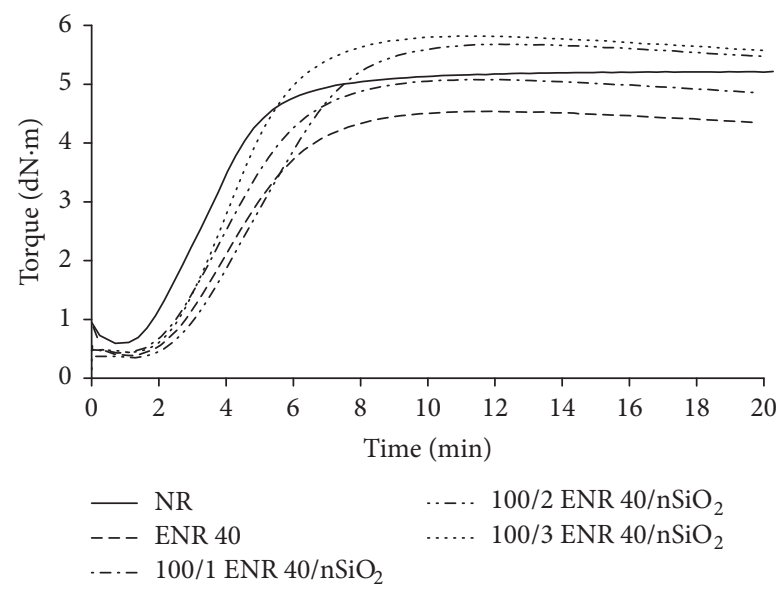

FIGURE 4: MDR rheographs of NR, ENR 40, and ENR 40/nSiO 2 nanocomposites.

TABLE 2: Cure characteristics of NR, ENR 40, and ENR 40/nSiO 2 nanocomposites.

\begin{tabular}{lccccc}
\hline \multirow{2}{*}{ Cure characteristic } & \multirow{2}{*}{ NR } & \multirow{2}{*}{ ENR 40 } & \multicolumn{3}{c}{ ENR 40/nSiO } \\
& & & $100 / 1$ & $100 / 2$ & $100 / 3$ \\
\hline$t_{\mathrm{s} 2}(\mathrm{~min})$ & 3.6 & 5.1 & 4.3 & 4.8 & 3.9 \\
$t_{90}(\mathrm{~min})$ & 6.0 & 7.2 & 6.9 & 7.9 & 6.8 \\
$\mathrm{CRI}\left(\mathrm{min}^{-1}\right)$ & 41.7 & 47.6 & 38.5 & 31.3 & 35.7 \\
$M_{\mathrm{L}}(\mathrm{dN} \cdot \mathrm{m})$ & 0.7 & 0.4 & 0.5 & 0.3 & 0.4 \\
$M_{\mathrm{H}}(\mathrm{dN} \cdot \mathrm{m})$ & 5.2 & 4.4 & 5.1 & 5.7 & 5.8 \\
$M_{\mathrm{H}}-M_{\mathrm{L}}(\mathrm{dN} \cdot \mathrm{m})$ & 4.5 & 4.0 & 4.6 & 5.4 & 5.4 \\
\hline
\end{tabular}

of the vulcanizate $[3,9,10] . M_{\mathrm{H}}-M_{\mathrm{L}}$ is a measure of the dynamic shear modulus, which indirectly indicates the extent of crosslinking (crosslink density) of the vulcanizate $[9,10,18,25]$. The $M_{\mathrm{L}}, M_{\mathrm{H}}$, and $M_{\mathrm{H}}-M_{\mathrm{L}}$ values of the ENR 40 were found to be lower than those of the NR (Table 2), indicating the lower viscosity of the uncured ENR 40 and also the lower elastic modulus and crosslink density of the ENR 40 vulcanizate. The lower viscosity of the uncured compound may be owing to the possible opening of epoxide rings and the degradation of ENR 40 molecules either during epoxidation or during compounding at high temperature, while the lower elastic modulus and crosslink density of the ENR 40 vulcanizate may be owing to the lower number of the $\mathrm{C}=\mathrm{C}$ in the ENR 40 compared to that in the NR [9]. However, the $M_{\mathrm{L}}$ values of ENR 40 and its nanocomposites were nearly the same, indicating that the $\mathrm{nSiO}_{2}$ at a very low loading had no effect on the viscosity of the uncured compounds, while the $M_{\mathrm{H}}$ and $M_{\mathrm{H}}-M_{\mathrm{L}}$ values of the nanocomposites noticeably increased compared to those of the ENR 40 as a consequence of the strong interaction between ENR 40 and $\mathrm{nSiO}{ }_{2}$ as previously mentioned.

3.2. Characterization of Vulcanized Samples. The mechanical properties of the samples both before and after aging at $100^{\circ} \mathrm{C}$ for $72 \mathrm{~h}$ in air are summarized in Table 2. It is seen that the tensile properties (tensile strength, M300, and elongation at break) and tear strength of the NR were all higher than those of the ENR 40. This is owing to the higher ability of NR to undergo strain crystallization as a result of its high molecular stereoregularity and also owing to the higher elasticity of NR that provided superior mechanical properties. Moreover, the epoxidation resulted in a reduced tendency to crystallize at high elongation of the synthesized ENR 40. Table 2 also shows a reduction in all the studied mechanical properties of NR and ENR 40 after aging as a result of the molecular chain scission and/or crosslink breakage at high temperature and oxygen content $[3,4]$. It is seen that the percentage retentions of tensile strength, M300, elongation at break, and tear strength of the NR were all lower than those of the ENR 40. This is because of a higher susceptibility to thermal oxidative degradation of NR, which was mainly owing to the high level of the $\mathrm{C}=\mathrm{C}$ in the main chain that gave rise to the lower retention values [4]. Therefore, changes in the mechanical properties of rubber products depended on the extent of such reactions that limited their useful lifetime at elevated temperature in the presence of atmospheric oxygen. However, the high rubber-rubber interaction could improve the aging resistance of the ENR 40.

The effects of $\mathrm{nSiO}_{2}$ on the mechanical properties of ENR 40 nanocomposites are also shown in Table 2 and Figure 5. As can be seen, the tensile properties and tear strength of the ENR 40 nanocomposites with three loadings of $\mathrm{nSiO}_{2}(1,2$ and $3 \mathrm{phr}$ ) were all higher than those of the neat ENR 40, owing to the reinforcing effect of $\mathrm{nSiO}_{2}$, but at $2 \mathrm{phr} \mathrm{nSiO}_{2}$ was the highest for all the mechanical properties. This may be attributed to a better dispersion of $\mathrm{nSiO}_{2}$ in the ENR 40 matrix, providing a greater filler-rubber interaction between the silanol and epoxide groups. This is an essential role for achieving the good mechanical properties. However, the decrease in the mechanical properties of the nanocomposite at $3 \mathrm{phrnSiO}$ may be owing to the agglomeration of an excess $\mathrm{nSiO}{ }_{2}$, leading to a poor dispersion of $\mathrm{nSiO}_{2}$ in the ENR 40 matrix, a reduction in contact area between $\mathrm{nSiO}_{2}$ and ENR 40, and also a filler-rubber interaction. However, the percentage retention in mechanical properties of all the ENR 40 nanocomposites was higher than that of the neat ENR 40, owing to a very high thermal resistance of the $\mathrm{nSiO}_{2}[25,26]$.

The DSC curves of the vulcanized NR, ENR 40, and ENR $40 / \mathrm{nSiO}_{2}$ nanocomposites are shown on the right side of Figure 3 , and the obtained $T_{\mathrm{g}}$ values are also presented in Table 1 . The $T_{\mathrm{g}}$ values of all the vulcanizates were higher than those of the corresponding unvulcanized samples according to the formation of crosslinks in the rubber matrix that restricted the flexibility of the rubber chains; hence $T_{\sigma}$ increased. In addition, all the $T_{\mathrm{g}}$ values of the vulcanized samples followed the same trend as those of the unvulcanized samples (Table 1). Among the nanocomposites, the ENR 40 filled with $2 \mathrm{phr} \mathrm{nSiO}_{2}$ exhibited the lowest $T_{\mathrm{g}}$ owing to a better dispersion of $\mathrm{nSiO}_{2}$ that caused a decrease of the ENR 40 being trapped within the $\mathrm{nSiO}_{2}$ network and so resulted in a higher mobility of the rubber chain segments; hence $T_{\mathrm{g}}$ decreased [30,31].

Figure 6 shows the storage modulus $\left(E^{\prime}\right)$, loss modulus $\left(E^{\prime \prime}\right)$, and loss tangent $(\tan \delta)$ curves obtained from the DMA analysis of the samples, and their $E^{\prime}\left(\right.$ at $\left.-65^{\circ} \mathrm{C}\right), T_{\mathrm{g}}$, and 


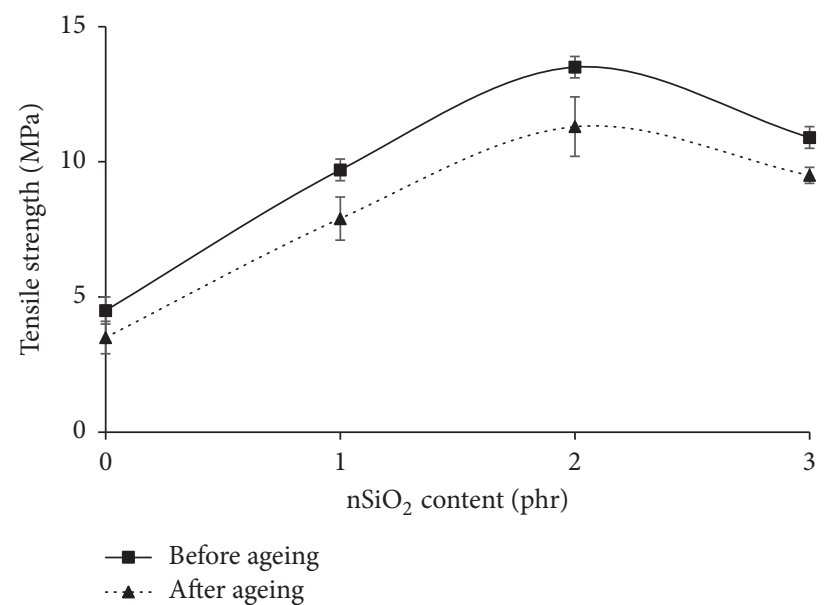

(a)

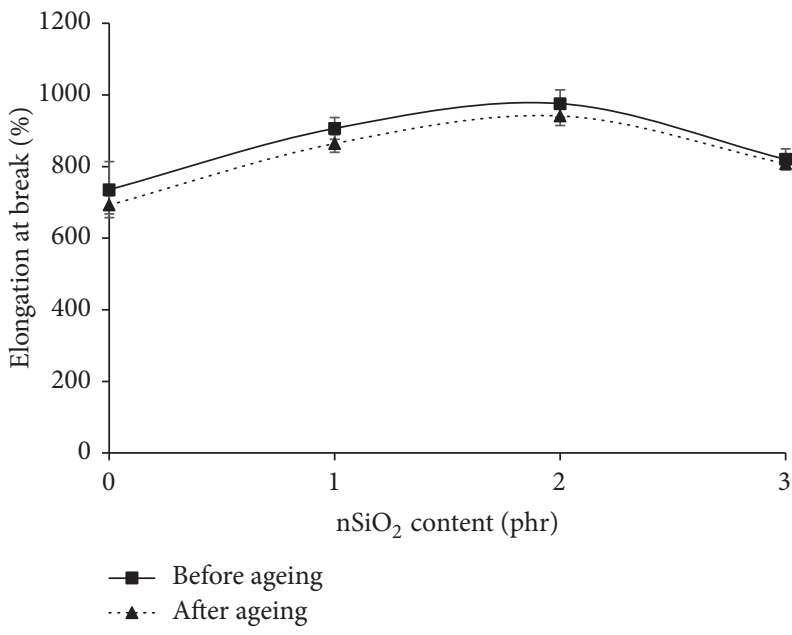

(c)

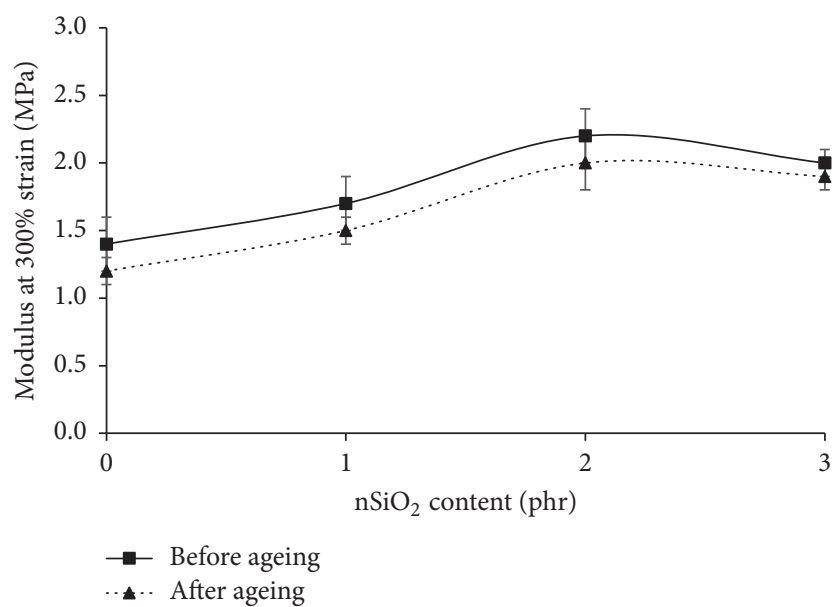

(b)

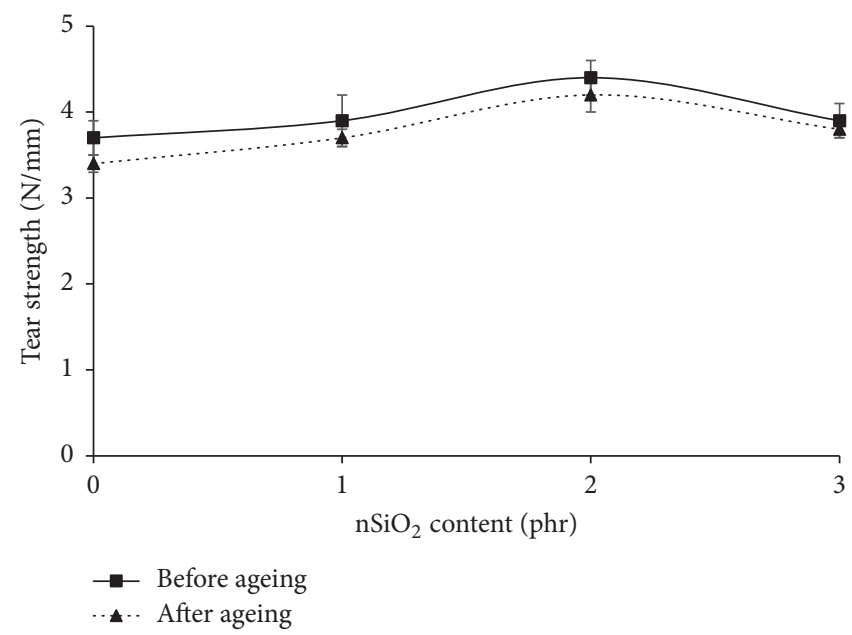

(d)

FIGURE 5: Mechanical properties of ENR 40/nSiO 2 nanocomposites in terms of (a) tensile strength, (b) M300, (c) elongation at break, and (d) tear strength.

$\tan \delta_{\max }$ (height of $\tan \delta$ peak) values are also listed in Table 1. According to Figure 6(a), the ENR 40 and ENR $40 / \mathrm{nSiO}_{2}$ nanocomposites had much higher $E^{\prime}$ values than the NR. The higher $E^{\prime}$ value of ENR 40 is again owing to the strong intermolecular force between epoxide groups that restricted the mobility of the ENR 40 chain segments. Additionally, all the ENR $40 / \mathrm{nSiO}_{2}$ nanocomposites exhibited higher $E^{\prime}$ values than the neat ENR 40. This may be owing to the good interaction between the $\mathrm{nSiO}_{2}$ and ENR 40 and also to the high stiffness of $\mathrm{nSiO}_{2}$ that restricted the mobility of the rubber chains as previously discussed. According to Figures 6(b) and 6(c), the $T_{\mathrm{g}}$ values derived from the temperatures at the $E^{\prime \prime}$ and $\tan \delta$ peaks followed the same behavior as that obtained from the DSC curves (Figure 3). It is seen that the $T_{\mathrm{g}}$ values of the ENR 40 and $\mathrm{ENR} 40 / \mathrm{nSiO}_{2}$ nanocomposites were also much higher than those of the NR according to the same reason as previously discussed. However, the $\tan \delta_{\max }$ values of the ENR 40 and $\mathrm{ENR} 40 / \mathrm{nSiO}_{2}$ nanocomposites were all lower than those of the NR. This indicated that the ENR 40 and $\mathrm{ENR} 40 / \mathrm{nSiO}_{2}$ nanocomposites were stiffer than the NR as a consequence of the strong intermolecular attraction or rubber-filler interaction as previously mentioned.

The thermal stability of the samples was evaluated by TGA, and their representative TG and derivative thermogravimetry (DTG) curves are shown in Figure 7. The derived $T_{\text {onset }}, T_{50 \%}, T_{\text {end set }}, T_{\text {max }}$, and $\%$ char values are also listed in Table 1. All the samples had similar TG and DTG curves and each one presented a two-step degradation. The degradation of the first step for all samples observed at $226-252^{\circ} \mathrm{C}$ $\left(T_{\text {onset 1 }}\right), 287-296^{\circ} \mathrm{C}\left(T_{\text {end set } 1}\right)$, and $268.5-284.8^{\circ} \mathrm{C}\left(T_{\max 1}\right)$ was attributed to the low molecular weight compounds such as nonrubber components and impurities as well as additives $[15,16]$ and has a weight loss of $6.7-8.1 \%$, whereas the second step observed at $362.7-379.7^{\circ} \mathrm{C}\left(T_{\text {onset } 2}\right), 419.4-435^{\circ} \mathrm{C}$ ( $\left.T_{\text {end set } 2}\right)$, and $385-401^{\circ} \mathrm{C}\left(T_{\max 2}\right)$ was attributed to the main degradation of rubber hydrocarbon, corresponding to the weight loss of $76.2-87.1 \%$. Additionally, $T_{50 \%}$ for all samples was in the range of $388.4-410.6^{\circ} \mathrm{C}$. As can be seen, $T_{\text {onset } 2}, T_{50 \%}, T_{\text {end set 2 }}$, and $T_{\max 2}$ of the ENR 40 were all higher than those of the NR, indicating that the thermal 


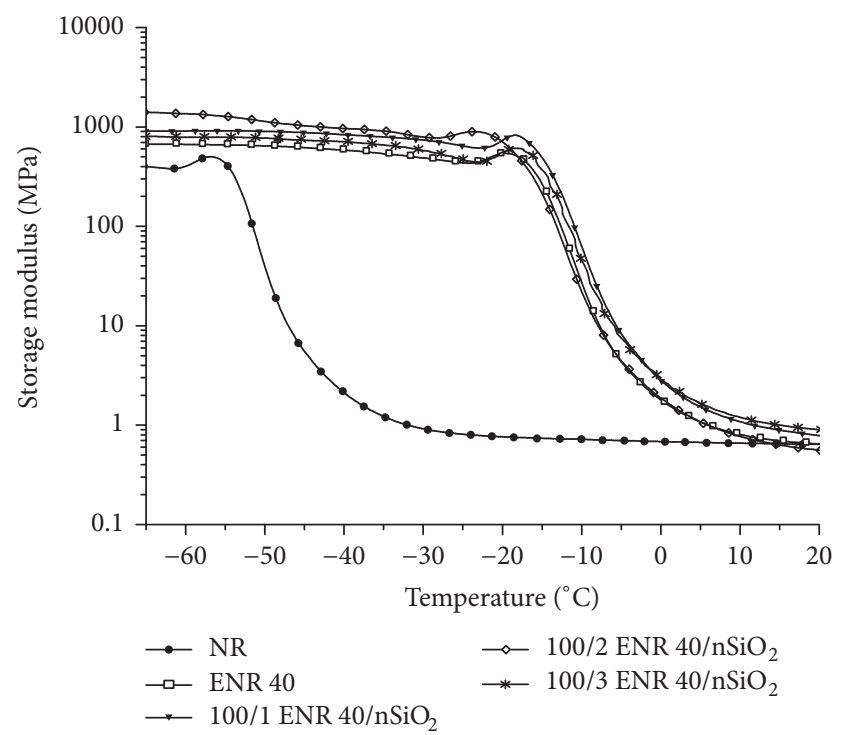

(a)

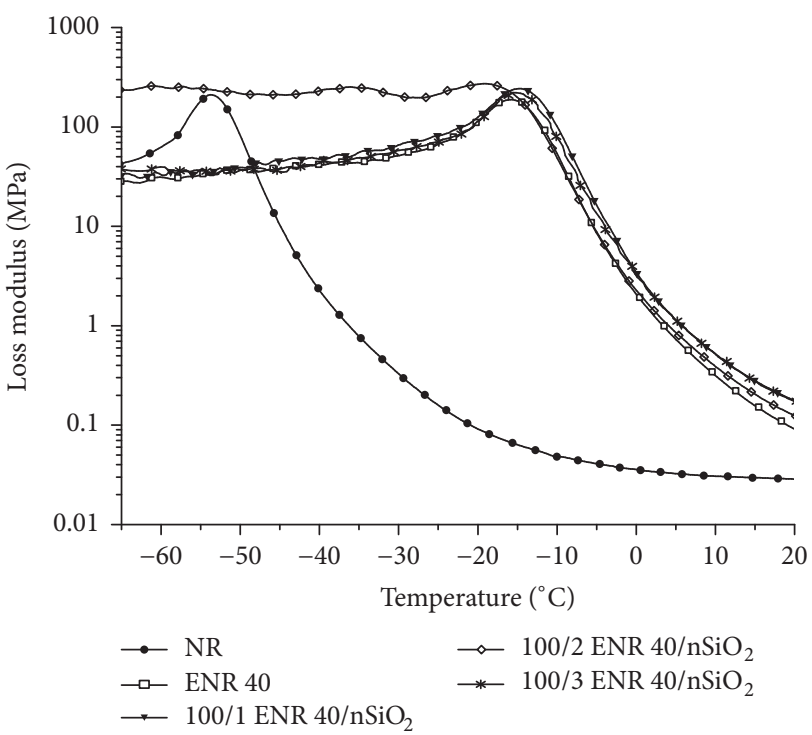

(b)

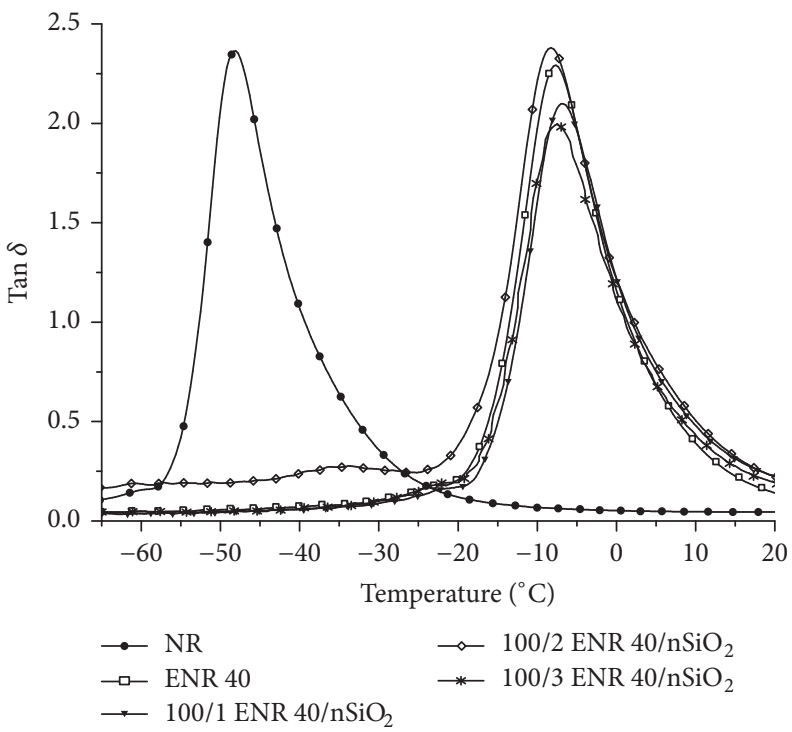

(c)

Figure 6: Dynamic mechanical properties of NR, ENR 40, and ENR 40/nSiO 2 nanocomposites in terms of (a) storage modulus, (b) loss modulus, and (c) $\tan \delta$.

stability of ENR 40 was improved. This is owing to the strong intermolecular attraction in ENR 40 caused by the insertion of oxygen atoms in the NR molecules and also to the high susceptibility to degradation of NR as previously mentioned. Moreover, the degradation temperatures from Table 3 also revealed that the addition of $\mathrm{nSiO}_{2}$ to the ENR 40 exhibited a dose-dependent increase in the thermal stability of the nanocomposites by shifting $T_{\text {onset } 2}, T_{50 \%}, T_{\text {end set } 2}$, and $T_{\max 2}$ towards higher temperatures compared to those of the neat ENR 40. This is owing to the high thermal stability of $\mathrm{nSiO}_{2}$ accompanied with a strong filler-rubber interaction through the hydrogen bonding that caused the degradation to occur at a higher temperature and that also hindered the mass transport during the thermal degradation process
[22-25]. It was also found that the char formation of the nanocomposites (13.4-16.6 wt\%) remarkably increased with increasing $\mathrm{nSiO}_{2}$ loading compared to that of the neat $\mathrm{NR}$ and ENR 40 (both at $6 \mathrm{wt} \%$ ) as shown in Figure 7 and Table 1. This is because $\mathrm{nSiO}_{2}$ is an inorganic nanofiller that can withstand high temperature and remain as residue even at $1,000^{\circ} \mathrm{C}$ and so delays and reduces the thermal degradation of the vulcanizates by restricting the permeability of volatile decomposition products out of the samples [4, 25].

The percentage volume change of the NR, ENR 40, and ENR 40/nSiO 2 nanocomposites after being immersed in ASTM oil number 1 (aniline point $\sim 124^{\circ} \mathrm{C}$ ) and ASTM oil number 3 (aniline point $\sim 90^{\circ} \mathrm{C}$ ) at $100^{\circ} \mathrm{C}$ for $72 \mathrm{~h}$ is presented in Table 4 . It is seen that the percentage volume 


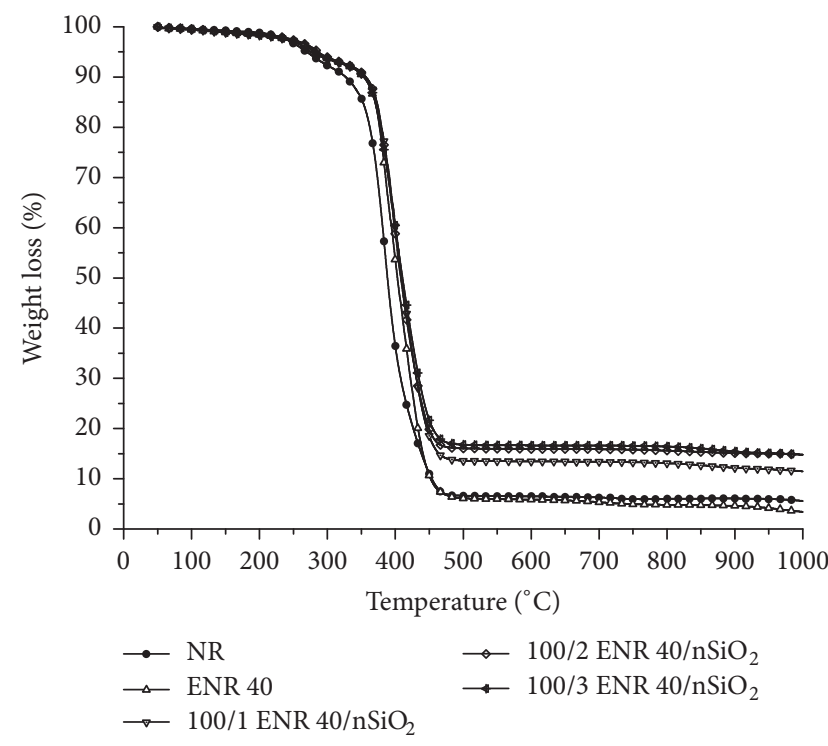

(a)

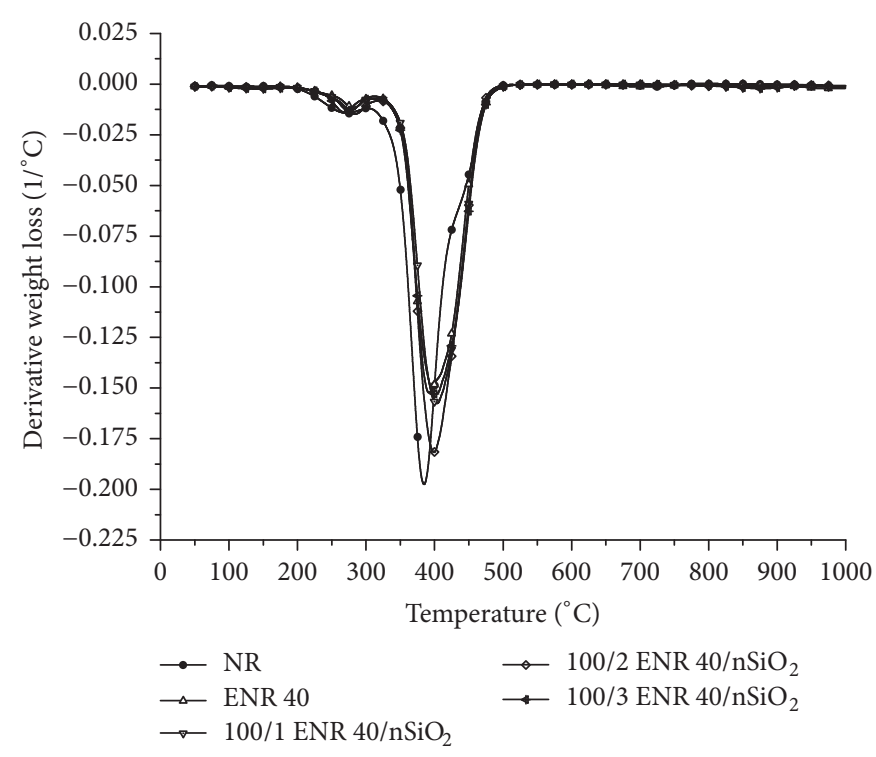

(b)

Figure 7: (a) TGA and (b) DTG thermograms of NR, ENR 40, and ENR 40/nSiO 2 nanocomposites.

TABLE 3: Mechanical properties and \% retention of NR, ENR 40, and ENR 40/nSiO ${ }_{2}$ nanocomposites.

\begin{tabular}{|c|c|c|c|c|c|}
\hline \multirow{2}{*}{ Mechanical properties } & \multirow{2}{*}{ NR } & \multirow{2}{*}{ ENR 40} & \multicolumn{3}{|c|}{ ENR $40 / \mathrm{nSiO}_{2}$} \\
\hline & & & $100 / 1$ & $100 / 2$ & $100 / 3$ \\
\hline \multicolumn{6}{|l|}{ Tensile strength } \\
\hline Before aging (MPa) & $13.4 \pm 0.7$ & $4.5 \pm 0.5$ & $9.7 \pm 0.4$ & $13.5 \pm 0.4$ & $10.9 \pm 0.4$ \\
\hline After aging (MPa) & $8.8 \pm 0.5$ & $3.5 \pm 0.6$ & $7.9 \pm 0.8$ & $11.3 \pm 1.1$ & $9.5 \pm 0.3$ \\
\hline Retention (\%) & 65.7 & 77.8 & 81.4 & 83.7 & 87.2 \\
\hline \multicolumn{6}{|l|}{ M300 } \\
\hline Before aging (MPa) & $2.4 \pm 0.2$ & $1.4 \pm 0.2$ & $1.7 \pm 0.2$ & $2.2 \pm 0.2$ & $2.0 \pm 0.1$ \\
\hline After aging (MPa) & $1.8 \pm 0.2$ & $1.2 \pm 0.1$ & $1.5 \pm 0.1$ & $2.0 \pm 0.2$ & $1.9 \pm 0.1$ \\
\hline Retention (\%) & 75 & 85.7 & 88.2 & 90.9 & 95 \\
\hline \multicolumn{6}{|l|}{ Elongation at break } \\
\hline Before aging (\%) & $949.0 \pm 26.3$ & $735.5 \pm 78.5$ & $906.5 \pm 30.1$ & $975.8 \pm 38.1$ & $820.3 \pm 29.2$ \\
\hline After aging (\%) & $739.6 \pm 42.5$ & $692.7 \pm 25.1$ & $864.4 \pm 24.5$ & $941.5 \pm 26.8$ & $808.2 \pm 15.5$ \\
\hline Retention (\%) & 77.9 & 94.2 & 95.4 & 96.5 & 98.5 \\
\hline \multicolumn{6}{|l|}{ Tear strength } \\
\hline Before aging $(\mathrm{N} / \mathrm{mm})$ & $4.6 \pm 0.1$ & $3.7 \pm 0.2$ & $3.9 \pm 0.3$ & $4.4 \pm 0.2$ & $3.9 \pm 0.2$ \\
\hline After aging $(\mathrm{N} / \mathrm{mm})$ & $4.0 \pm 0.2$ & $3.4 \pm 0.1$ & $3.7 \pm 0.1$ & $4.2 \pm 0.2$ & $3.8 \pm 0.1$ \\
\hline Retention (\%) & 87 & 91.9 & 94.9 & 95.4 & 97.4 \\
\hline
\end{tabular}

change of NR in both oils was much higher than that of the ENR 40 and ENR $40 / \mathrm{nSiO}_{2}$ nanocomposites, indicating that the epoxidation significantly improved their oil resistance. Moreover, the ENR $40 / \mathrm{nSiO}_{2}$ nanocomposites exhibited a $\mathrm{nSiO}_{2}$ load-dependent higher oil resistance than the neat ENR 40 according to the interaction between the epoxide groups of the ENR 40 and the $\mathrm{Si}-\mathrm{OH}$ groups on the $\mathrm{nSiO}_{2}$ and also to their higher crosslink density that limited the penetration of oils into the rubber matrix. However, the volume change of the samples in ASTM oil number 3 was much higher than that in ASTM oil number 1 . This is owing to the fact that the lower the aniline point the more severe the swelling action.

\section{Conclusions}

In this work, the ENR 40 was successfully synthesized via in situ performic epoxidation of $\mathrm{NR}$ in the latex state using a fixed molar ratio of $\mathrm{HCOOH} / \mathrm{H}_{2} \mathrm{O}_{2}$ to isoprene unit of $1 / 0.75$ in the presence of a surfactant at $50^{\circ} \mathrm{C}$ for $8 \mathrm{~h}$. Beside the epoxide groups, the ring-opened structures were also observed in the as-synthesized ENR 40. The resulting ENR 40 was melt mixed with three loadings of $\mathrm{nSiO}_{2}(1,2$, and $3 \mathrm{phr})$ and then vulcanized as usual in a sulfur curing system using TBzTD as a noncarcinogenic accelerator, which resulted into nitrosamine free cure. The curing characteristics, mechanical properties, thermal behaviors, dynamic mechanical 
TABLE 4: Oil resistance of NR, ENR 40, and ENR 40/nSiO ${ }_{2}$ nanocomposites.

\begin{tabular}{|c|c|c|c|c|c|}
\hline \multirow[t]{2}{*}{ Oil resistance } & \multirow[t]{2}{*}{ NR } & \multirow[t]{2}{*}{ ENR 40} & \multicolumn{3}{|c|}{ ENR $40 / \mathrm{nSiO}_{2}$} \\
\hline & & & $100 / 1$ & $100 / 2$ & $100 / 3$ \\
\hline \multicolumn{6}{|l|}{ Volume change } \\
\hline In IRM 901 oil (\%) & 111.3 & 7.6 & 4.0 & 6.5 & 3.7 \\
\hline In IRM 903 oil (\%) & 244.3 & 96.9 & 74.1 & 87.5 & 75.4 \\
\hline
\end{tabular}

properties, and oil resistance of the prepared ENR $40 / \mathrm{nSiO}_{2}$ nanocomposites were investigated and compared with NR and neat ENR 40 . The results revealed that $t_{\mathrm{s} 2}$ and $t_{90}$ of ENR $40 / \mathrm{nSiO}_{2}$ nanocomposites were slightly longer than those of NR but slightly shorter than those of ENR 40. However, the CRI of all ENR $40 / \mathrm{nSiO}_{2}$ nanocomposites was lower than that of NR and ENR 40, while the crosslink density $\left(M_{\mathrm{H}}-\right.$ $M_{\mathrm{L}}$ ) was slightly higher. The mechanical properties (tensile properties and tear strength) of ENR 40 for both before and after aging at $100^{\circ} \mathrm{C}$ for $72 \mathrm{~h}$ were found to be improved as a result of the incorporation of $\mathrm{nSiO}_{2}$ (all, but 2 phr optimal), while the \% retention in all mechanical properties of ENR $40 / \mathrm{nSiO}_{2}$ nanocomposites was higher than that of $\mathrm{NR}$ and ENR 40 in a dose-dependent manner. The $T_{\mathrm{g}}, E^{\prime}$ at $-65^{\circ} \mathrm{C}$, thermal stability, and oil resistance (in ASTM Oil number 1 and number 3 ) of ENR 40 were also enhanced with the addition of $\mathrm{nSiO}_{2}$ (all, but 1 phr optimal).

\section{Conflicts of Interest}

The authors declare that there are no conflicts of interest regarding the publication of this paper.

\section{Acknowledgments}

The authors gratefully acknowledge the 100th Anniversary Chulalongkorn University Fund for Doctoral Scholarship and also the 90th Anniversary Chulalongkorn University Fund (Ratchadaphiseksomphot Endowment Fund) for financial support.

\section{References}

[1] M. M. Hassan, A. A. Abd El-Megeed, and N. A. Maziad, "Evaluation of curing and physical properties of NR/SBR blends using radiation-grafting copolymer," Polymer Composites, vol. 30, no. 6, pp. 743-750, 2009.

[2] D. Derouet, P. Intharapat, Q. N. Tran, F. Gohier, and C. Nakason, "Graft copolymers of natural rubber and poly(dimethyl(acryloyloxymethyl)phosphonate) (NR-g-PDMAMP) or poly(dimethyl(methacryloyloxyethyl)phosphonate) (NR-g-PDMMEP) from photopolymerization in latex medium," European Polymer Journal, vol. 45, no. 3, pp. 820-836, 2009.

[3] Y. S. R. Yahya, A. R. Azura, and Z. Ahmad, "Effect of curing systems on thermal degradation behaviour of natural rubber (SMR CV 60)," Journal of Physical Science, vol. 22, no. 2, pp. 1-14, 2011.

[4] Z. X. Ooi, H. Ismail, and A. A. Bakar, "A comparative study of aging characteristics and thermal stability of oil palm ash, silica, and carbon black filled natural rubber vulcanizates," Journal of Applied Polymer Science, vol. 130, no. 6, pp. 4474-4481, 2013.
[5] B. Thongnuanchan, K. Nokkaew, A. Kaesaman, and C. Nakason, "Epoxidized natural rubber-bonded para rubber wood particleboard," Polymer Engineering and Science, vol. 47, no. 4, pp. 421-428, 2007.

[6] K. Jai-Eau, E. Wimolmala, and N. Sombatsompop, "Cure behavior and antimicrobial performance of sulfur-cured natural rubber vulcanizates containing 2-hydroxypropyl-3-piperazinylquinolinecarboxylic acid methacrylate or silver-substituted zeolite," Journal of Vinyl and Additive Technology, vol. 19, no. 2, pp. 123-131, 2013.

[7] K. Abhitha and K. Thomas, "Safe vulcanization system for heat resistant natural rubber products for engineering applications," American Journal of Engineering Research, vol. 3, p. 13, 2013.

[8] R. Yoksan, "Epoxidized natural rubber for adhesive applications," Kasetsart Journal (Natural Science), vol. 42, pp. 325-332, 2008.

[9] C. M. Vu, H. T. Vu, and H. J. Choi, "Fabrication of natural rubber/epoxidized natural rubber/nanosilica nanocomposites and their physical characteristics," Macromolecular Research, vol. 23, no. 3, pp. 284-290, 2015.

[10] P. L. Teh, Z. A. M. Ishak, A. S. Hashim, J. Karger-Kocsis, and U. S. Ishiaku, "Effects of epoxidized natural rubber as a compatibilizer in melt compounded natural rubber-organoclay nanocomposites," European Polymer Journal, vol. 40, no. 11, pp. 2513-2521, 2004.

[11] A. S. M. Bashir, Y. Manusamy, T. L. Chew, H. Ismail, and S. Ramasamy, "Mechanical, thermal, and morphological properties of (eggshell powder)-filled natural rubber latex foam," Journal of Vinyl and Additive Technology, vol. 23, no. 1, pp. 312, 2015.

[12] V. Tanrattanakul, B. Wattanathai, A. Tiangjunya, and P. Muhamud, "In situ epoxidized natural rubber: improved oil resistance of natural rubber," Journal of Applied Polymer Science, vol. 90, no. 1, pp. 261-269, 2003.

[13] S. Gnecco, A. Pooley, and M. Krause, "Epoxidation of lowmolecular-weight Euphorbia lactiflua natural rubber with "in situ” formed performic acid," Polymer Bulletin, vol. 37, no. 5, pp. 609-615, 1996.

[14] J. E. Davey and M. J. R. Loadman, "Chemical demonstration of the randomness of epoxidation of natural rubber," British Polymer Journal, vol. 16, no. 3, pp. 134-138, 1984.

[15] Z.-Q. Zeng, H.-P. Yu, Q.-F. Wang, and G. Lu, "Effects of coagulation processes on properties of epoxidized natural rubber," Journal of Applied Polymer Science, vol. 109, no. 3, pp. 1944-1949, 2008.

[16] W. A. K. Mahmood and M. H. Azarian, "Thermal, surface, nanomechanical and electrical properties of epoxidized natural rubber (ENR-50)/polyaniline composite films," Current Applied Physics, vol. 15, no. 5, pp. 599-607, 2015.

[17] N. V. Bac, L. Terlemezyan, and M. Mihailov, "On the stability and in situ epoxidation of natural rubber in latex by performic acid," Journal of Applied Polymer Science, vol. 42, no. 11, pp. 2965-2973, 1991. 
[18] Y. Wang, X. Zhang, J. Oh, and K. Chung, "Effect of carbon black on self-crosslinking network structure of polychloroprene rubber and epoxidized natural rubber blends," Polymer Composites, 2015.

[19] P. K. Chattopadhyay, U. Basuli, and S. Chattopadhyay, "Studies on novel dual filler based epoxidized natural rubber nanocomposite," Polymer Composites, vol. 31, no. 5, pp. 835-846, 2010.

[20] P. Sheth and R. N. Desai, "Replacing TMTD with nitrosamine free TBzTD accelerator in curing of rubber," International Journal for Scientific Research \& Development, vol. 1, no. 3, pp. 532-535, 2013.

[21] T. E. Motaung, A. S. Luyt, and S. Thomas, "Morphology and properties of NR/EPDM rubber blends filled with small amounts of titania nanoparticles," Polymer Composites, vol. 32, no. 8, pp. 1289-1296, 2011.

[22] M. Jarnthong, C. Nakason, N. Lopattananon, and Z. Peng, "Influence of incorporation sequence of silica nanoparticles on morphology, crystallization behavior, mechanical properties, and thermal resistance of melt blended thermoplastic natural rubber," Polymer Composites, vol. 33, no. 11, pp. 1911-1920, 2012.

[23] V. A. Doan, S. Nobukawa, S. Ohtsubo, T. Tada, and M. Yamaguchi, "Selective migration of silica particles between rubbers," Journal of Polymer Research, vol. 20, no. 5, article 145, 2013.

[24] W. Kaewsakul, K. Sahakaro, W. K. Dierkes, and J. W. M. Noordermeer, "Verification of interactions between silica and epoxidised squalene as a model for epoxidised natural rubber," Journal of Rubber Research, vol. 17, no. 3, pp. 129-142, 2014.

[25] M. R. Pourhossaini and M. Razzaghi-Kashani, "Grafting hydroxy-terminated polybutadiene onto nanosilica surface for styrene butadiene rubber compounds," Journal of Applied Polymer Science, vol. 124, no. 6, pp. 4721-4728, 2012.

[26] N. Jon, N. A. Samad, N. A. Abdullah, I. Abdullah, and R. Othaman, "Influence of silica addition on the properties of epoxidised natural rubber/polyvinyl chloride composite membrane," Journal of Applied Polymer Science, vol. 129, no. 5, pp. 2789-2795, 2013.

[27] A. Thitithammawong, N. Ruttanasupa, and C. Nakason, "Preparation and properties of chlorinated epoxidised natural rubber latex and its latex-based adhesive," Journal of Rubber Research, vol. 15, no. 1, pp. 19-34, 2012.

[28] S.-H. Chough and D.-H. Chang, "Kinetics of sulfur vulcanization of NR, BR, SBR, and their blends using a rheometer and DSC," Journal of Applied Polymer Science, vol. 61, no. 3, pp. 449454, 1996.

[29] H. Ismail, R. B. Abdul Majid, and R. Mat Taib, "Effects of dynamic vulcanization on tensile, morphological, and swelling properties of poly(vinyl chloride) (PVC)/epoxidized natural rubber (ENR)/(Kenaf core powder) composites," Journal of Vinyl and Additive Technology, vol. 22, no. 3, pp. 206-212, 2016.

[30] P. Saramolee, K. Sahakaro, N. Lopattananon, W. K. Dierkes, and J. W. M. Noordermeer, "Comparative properties of silicaand carbon blackreinforced natural rubber in the presence of epoxidized lowmolecular weight polymer," Rubber Chemistry and Technology, vol. 87, no. 2, pp. 320-339, 2014.

[31] L. Qu, G. Yu, L. Wang, C. Li, Q. Zhao, and J. Li, "Effect of filler-elastomer interactions on the mechanical and nonlinear viscoelastic behaviors of chemically modified silica-reinforced solution-polymerized styrene butadiene rubber," Journal of Applied Polymer Science, vol. 126, no. 1, pp. 116-126, 2012. 

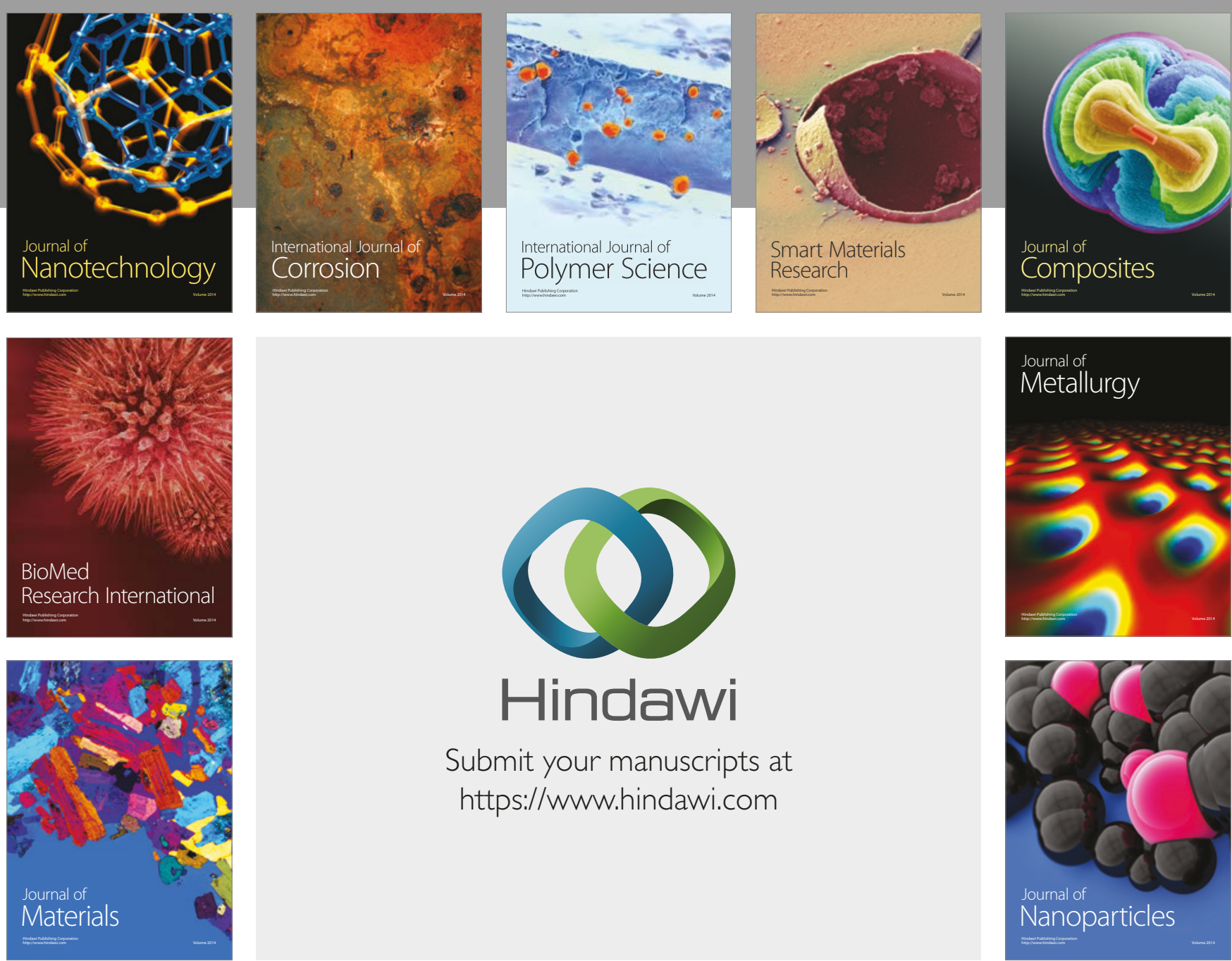

\section{Hindawi}

Submit your manuscripts at

https://www.hindawi.com
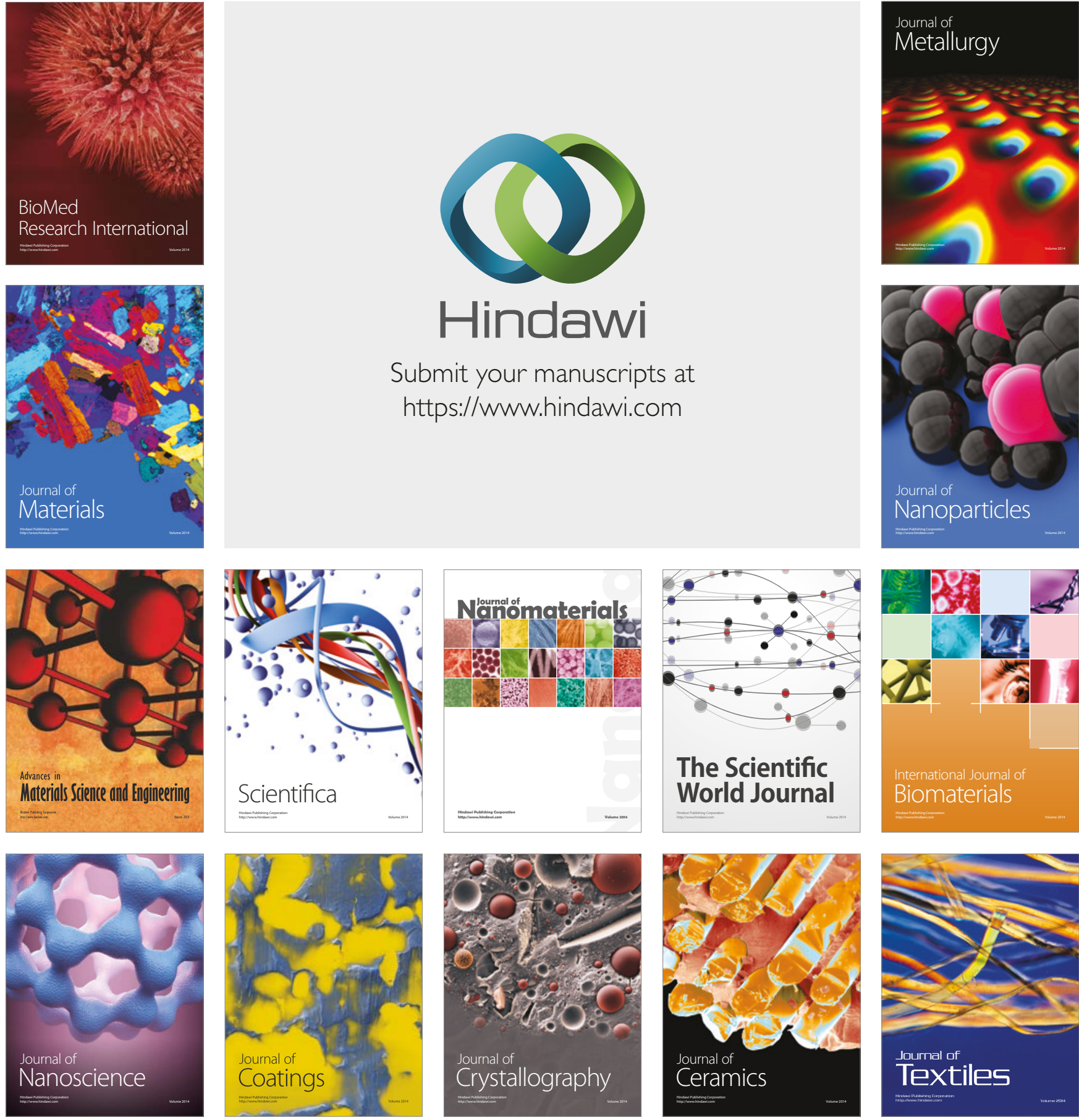

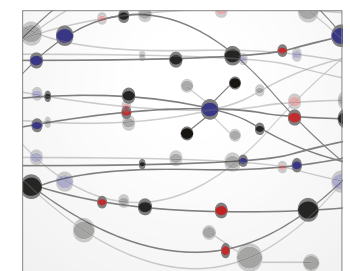

The Scientific World Journal
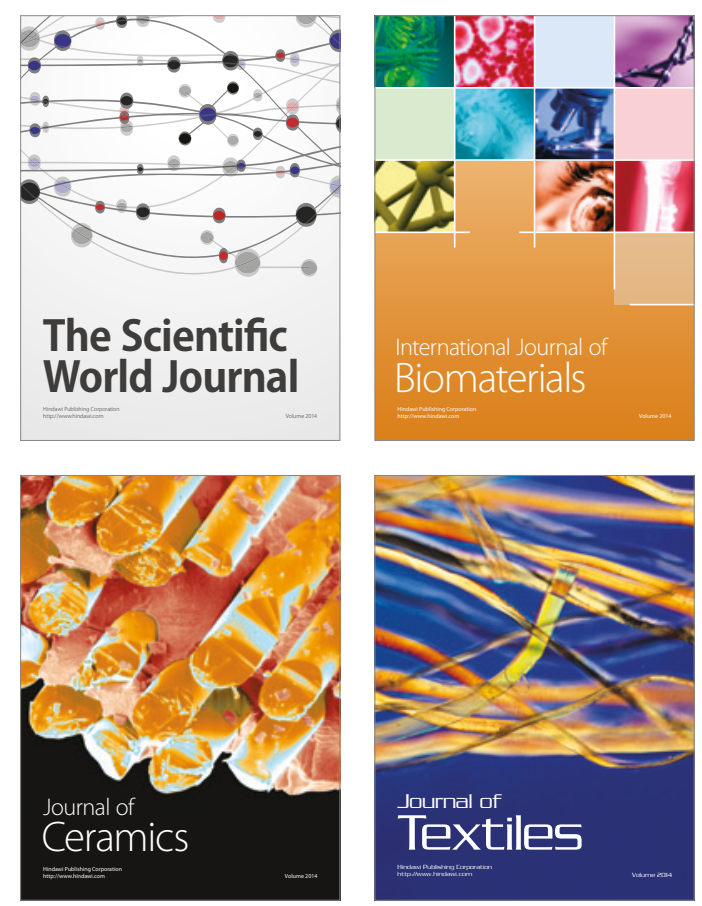